\title{
The effects of schedules of training upon the development of a conditioned reinforcer'
}

\author{
NORMAN KASS, AKN BEARDSHALL AND HELEN WILSON
}

SAN DIEGO STATE COLLEGE

One hundred twenty children were employed in a free operant situation to determine the effects of training schedules upon the establishment of a conditioned reinforcer. The variables employed were reinforcement schedule, the presence or absence of a light stimulus during training and the presence or absence of a light stimulus during extinction. There was no evidence that pairing of a neutral stimulus with primary reinforcement under a continuous or intermittent schedule facilitated its development as a conditioned reinforcer. The results indicate that the schedule of reinforcement during training is the major determinant of number of responses during extinction.

A number of studies in the area of primary reinforcement have shown that the resistance to extinction is an increasing function of the number of unrewarded trials during training (Kass, 1962; Lewis \& Duncan, 1957). The functional relationship is often interpreted in terms of a discrimination hypothesis; that is, resistance to extinction is inversely related to the similarity between acquisition and extinction conditions.

Since there is evidence that a secondary reinforcer acquires its power through the same procedures which determine the strength of a response with primary reinforcement (Myers, 1958), it might be expected that the phenomena of conditioned reinforcement could also be explained in terms of a discrimination hypothesis. Experiments in this area, however, have produced conflicting results (Fort, 1961; Fox \& King, 1961). While some studies have presented evidence that conditioned reinforcement phenomena can be explained in terms of discrimination (Bitterman, Feddersen, \& Tyler, 1953; Weiss \& Reed, 1962), others indicate that it is something more than a result of the discriminability between training and testing procedures (Saltzman, 1949).

The purpose of the present study was to investigate the effects of discrimination and training schedules upon the establishment of a conditioned reinforcer.

\section{Subjects}

The Ss were 120 elementary school children between the ages of 7.5 and 8.2 years. Approximately equal numbers of males and females were randomly assigned to each experimental condition.

\section{Apparatus}

The S panel consisted of a simulated slot machine with a handle mounted on the right side. Pulling the handle to the "down" position dispensed pennies into a cup at the bottom of the front panel. A plastic hemisphere (dome) protruded from the center of the machine. Two $15 \mathrm{w}$ red lamps were mounted directly behind a frosted upper portion of the dome. The lower half of the dome was clear, and displayed a large number of pennies throughout the experiment. The presentation of light stimuli, dispensing of pennies, and recording of responses were controlled by electronic programing and recording equipment located in a room to the rear of the experimental room.

The light stimulus was off when the handle was in the "up" position. When $S$ pulled the handle to the "down" position, the light came on $.5 \mathrm{sec}$. before the penny was dispensed, and remained on for $1 \mathrm{sec}$. until the coin appeared in the reward well.

\section{Procedure}

As $S$ stood in front of the apparatus he was told that in this game he was to try to obtain as many pennies from the machine as he possibly could. The $S$ was then shown the display of toys which could be bought with the pennies, following which he was told how to play the game. Each $S$ received his toy after everyone in his classroom had played the game. Eight Ss failed to complete the acquisition series and were replaced. Design

The variables employed were schedules of reinforcement $50 \%$ or $100 \%$, the presence or absence of a light stimulus during training, and the presence or absence of a light stimulus during extinction. Each $\mathrm{S}$ was given 24 conditioning trials and an extinction series. During acquisition the Ss in the $100 \%$ condition received a penny as reinforcement ( $\mathrm{PR}$ ) on each acquisition trial, the $\mathrm{Ss}$ in the $50 \%$ reinforcement condition received a $\mathrm{p}^{\mathbf{R}}$ randomly on half of the acquisition trials. Half of the Ss under each training condition received a light stimulus ( $\mathrm{Sr}$ ) paired with the $\mathrm{PR}$ during the acquisition series. The other half received no $\mathrm{S}^{\mathbf{r}}$.

For those Ss who received a Sr paired with $\mathrm{PR}$ during acquisition, half were extinguished with the $\mathbf{S}^{\mathbf{r}}$ presented alone on a reinforcement schedule identical to that used during training to test for its conditioned reinforcement $(\mathbf{S R})$ effect. The other half received no $\mathrm{S}^{\mathrm{r}}$ during extinction and served as a control for the $\mathrm{SR}$ effect. For those $\mathrm{Ss}$ who received only $\mathrm{pR}$ during acquisition half were extinguished with the $\mathrm{s}^{r}$ alone on a reinforced schedule identical to the $\mathrm{PR}$ schedules used during training to test for the novelty effect of the light stimulus, the other half received nothing during extinction and served as a test of the schedule of reinforcement during training.

The $50 \%$ reinforcement groups were used to deter- 
Table 1. Design of Experiment and Mean Log Number of Extinction Responses for Each Group

\begin{tabular}{|c|c|c|c|c|}
\hline Reinforcement & \multicolumn{4}{|c|}{ Light Stimulus Condition During Training } \\
\hline & $\begin{array}{l}\text { Light } \\
\text { Present } \\
R_{\text {Effect }}\end{array}$ & $\begin{array}{c}\text { Absent } \\
\text { (Control) }\end{array}$ & $\begin{array}{l}\text { ition Durin } \\
\text { Present } \\
\text { (Novelty } \\
\text { Effect) }\end{array}$ & $\begin{array}{c}\text { gextinction } \\
\text { Absent } \\
\text { (Schedules of } \\
\text { Reinforcement } \\
\text { Effect) }\end{array}$ \\
\hline 100 & .7388 & .6477 & .6305 & .8990 \\
\hline 50 & 1.6929 & 1.9233 & 1.5360 & 1.6733 \\
\hline
\end{tabular}

mine the effects of intermittency under the above conditions.

The study thus employed a 2 by 2 by 2 design with $15 \mathrm{Ss}$ in a cell. The Ss were randomly assigned to the resulting eight experimental groups.

\section{Results and Discussion}

To reduce heterogeneity of variance among the cells a $\log$ transformation was performed on the number of responses made during the extinction period. The design of the study along with the mean log number of extinction responses for each group is presented in Table 1.

It can be seen from Table 1 that the 50\% reinforcement groups show the usual partial reinforcement effect as compared to the continuous reinforcement group. For the condition which received the sr during training, there appears to be little difference in rate of extinction between the Ss who received the stimulus during testing and those who did not. It can also be seen that the condition which tested for the effect of the schedules of reinforcement did not differ from the condition under which we would expect an $\mathrm{SR}$ effect. The training schedules under both these conditions were identical except that for the $S R$ groups a light stimulus was paired with the $\mathrm{PR}^{\mathrm{R}}$ during training and present alone on an identical schedule during extinction. The conditions which tested for the novelty effect and controlled for the $\mathbf{S}^{R}$ effect showed the presence or absence of the light stimulus had little effect on extinction.

In the analysis of variance, differences associated with schedules of reinforcement were highly significant, $F=95.02, \mathrm{df}=1 / 112, \mathrm{p}<.001$. None of the other main effects or interaction terms was significant. From the data it would seem that the schedule of reinforcement during training is the major determinant of number of responses during extinction. The presence of a light seems to be of little importance; this is true for conditions under which we would expect the stimulus to take on acquired reward value $\left(S^{R}\right)$ or when it served as a novel stimulus.

These results do not readily lend themselves to interpretation of secondary reinforcement effects in terms of a discrimination hypothesis. Pairing of a neutral stimulus with $\mathrm{PR}$ during training and presenting this stimulus alone during extinction did not differentially affect response rate as compared to the conditions which had identical training procedures but nothing during extinction. The same non-significant difference was also found for the condition which had a novel stimulus present during extinction compared to the condition which did not have this stimulus present during training or extinction. There was no evidence that pairing of a neutral stimulus with primary reinforcement under a continuous or intermittent schedule facilitated its development as a secondary reinforcer. Failure of the light stimulus to acquire conditioned reinforcing properties is consistent with other findings in operant situations with children (Myers, Craig, \& Myers, 1961; Kass \& Wilson, 1966).

\section{Reterences}

Bitterman, M. E., Feddersen, W. E., \& Tyler, D. W. Secondary reinforcement and the discrimination hypothesis. Amer. J. Psychol, $1953,66,456-464$.

Duncan, D. B. Multiple range test and multiple F tests. Biometrics, $1955,11,1-42$.

Fort, J. G. Secondary reinforcement with preschool children. Child Develpm., 1961, 32, 755-764.

Fox, R. E., \& King, R. A. The effects of reinforcement scheduling on the strength of a secondary reinforcer. $J$. comp. physiol. Psychol., 1961, 54, 266-269.

Kass, N. Resistance to extinction as a function of age and schedules of reinforcement. J. exp. Psychol., 1962, 64, 249-252.

Kass, N., \& Wilson, H. Resistance to extinction as a function of percentage of reinforcement, number of training trials, and conditioned reinforcement. J. exp. Psychol., 1966, in press.

Lewis, D. J., \& Duncan, C. P. Expectation and resistance to extinction of a lever-pulling response as functions of percentage of reinforcement and amount of reward. J. exp. Psychol., 1957 , $54,115-120$.

Myers, J. L. Secondary reinforcement: a review of recent experimentation. Psychol. Bull., 1958, 55, No. 5.

Myers, N. A., Craig, C. J., \& Myers, J. L. Secondary reinforcement as a function of the number of reinforced trials. Child Develpm., $1961,32,765-772$.

Saltzman, I. J. Maze learning in the absence of primary reinforcement: a study of secondary reinforcement. J. comp. physiol. Psychol., 1949, 42, 161-163.

Weiss, S. J., \& Reed, L. Secondary reinforcement as a suppressor of rate of responding in the free operant situation. $J$. comp. physiol. Psychol., 1962, 55, 1016-1019.

\section{Note}

1. This study was supported by funds from National Institute of Mental Health Grant MH 06806-01. The authors wish to express their appreciation for the cooperation of Burton Tiffany, Supt. of Schools, and the principals and teachers of Lauderbach and Rosebank Elementary Schools, Chula Vista; Fr. Richard K. Nale, Rector, and the teachers of St. John's Episcrpal Day School, Chula Vista; and, Fr. William K. Hart, Headmaster, and the teachers of All Saints Episcopal Day School, San Diego. 